\title{
PATRIMONIOS CORPORALES ANCESTRALES DEL PUEBLO INDÍGENA ZENÚ. EL CARGAMENTO E' CASA COMO ESCENARIO DEL MONTUCUY ENTRE BAILES, JUEGOS, PITO ATRAVESAO Y GAITAS ${ }^{1}$
}

\author{
CORPORAL ANCESTRAL HERITAGE OF ZENÚ INDIGENOUS TOWN. THE CARGAMENTO E' CASA \\ LIKE A MONTUCUY SCENARIO BETWEEN DANCES, GAMES, \\ ATRAVESAO WHISTLE AND BAGPIPES
}

Jairzinho Francisco Panqueba Cifuentes ${ }^{2}$

\section{Resumen}

La incursión europea en América hizo posible una serie de adaptaciones y múltiples conjugaciones en las prácticas de vida cotidiana que, pese a transformarse, conservaron su matriz cultural. En el caso del pueblo indígena zenú, el montucuy mencionado en los documentos de la época colonial como: "juntas de vino de palma, aguardiente y chicha donde habían juegos y bailes con música de gaitas", ha seguido fungiendo como fuente lúdica de combinaciones. La expresión montucuy, caída en desuso en el territorio zenú, es actualmente dinamizada con otros nombres para diversas actividades cotidianas. El término circula como patrimonio corporal ancestral en los juegos, las fiestas, los bailes y las ritualidades acaecidas entre las sonoridades del pito atravesao y las gaitas, instrumentos musicales que se armonizan con tambores, guaches y tamboras. Ejemplo de ello es el ritual del Cargamento e' casa, una celebración que fortalece los compadrazgos y las solidaridades en torno al esfuerzo físico, animando las energías con alimentos, bebidas y distintas manifestaciones de jolgorio. El Cargamento e' casa evoca y convoca la imaginería lúdica zenú como un tributo - legado- de sus movimientos desde el juego, sus fuerzas ancestrales, el vigor de sus gentes y el poder de la solidaridad.

Palabras claves: danza, Tuchín, lúdica, etnicidades, ritual, fiesta.

\section{Abstract}

European foray into America made possible a series of adaptations and multiple conjugations everyday practices that although transformed, they retained their cultural matrix. In the case of Zenú indigenous town, the montucuy mentioned in documents from the colonial era as 'boards of palm wine, brandy and chicha they had games and dances with bagpipe music', has continued serving as source playful combinations. The expression 'montucuy' obsolescence in Zenú territory, is now streamlined with other names for various daily activities. The montucuy circulates like a corporal ancestral heritage in games, festivals, dances and ritualidades occurred between atravesao whistle and sounds of bagpipes, musical instruments that harmonize with drums, gouaches and drums. One example is the ritual of "Cargamento e' casa", a celebration that strengthens cronyism and solidarity around the physical effort, encouraging energy food, beverages and various manifestations of revelry. Loading and 'house evokes and summons the playful imagery Zenú as a tribute - legacy - their movements from play, their ancestral forces, the force of the people and the power of solidarity.

Keywords: dance, Tuchín, lúdica, ethnicity, rituality, parties

1 Este artículo está basado en la investigación titulada: "Montucuy en Tuchín. Patrimonios corporales ancestrales del pueblo indígena zenú, en los juegos y bailes de gaitas y pito atravesao". Para su realización el autor recibió una beca del Ministerio de Cultura de Colombia, convocatoria: "Cuerpo y Memoria de la Danza 2014".

2 Aprehendedor de saberes ancestrales y de la vida cotidiana. Dr. Ciencias Sociales especialidad Antropología Social por el Centro de Investigaciones y Estudios Superiores en Antropología Social (CIESAS)-Guadalajara, Jalisco, México. Magíster en Ciencias Sociales con énfasis en Estudios Étnicos por la Facultad Latinoamericana de Ciencias Sociales (Flacso), Ecuador. Licenciado en Educación Física por la Universidad Pedagógica Nacional, Bogotá, Colombia. Docente Colegio San Bernardino, territorio muisca de Bosa en Bogotá, Colombia. Correo electrónico: panqueba@gmail.com 
Fecha de recepción: 15 de mayo de 2015

Fecha de aprobación: 17 de septiembre de 2015

Para citar este artículo:

Panqueba, J.F. (2015). Patrimonios corporales ancestrales del pueblo indígena zenú. El cargamento e' casa como escenario del montucuy entre bailes, juegos, pito atravesao y gaitas. Lúdica Pedagógica, (22), 21-31.

\section{INTRODUCCIÓN A LA FIESTA ZENÚ}

Durante el XVII Festival Artesanal y Cultural del Sombrero Fino Vueltiao ${ }^{3}$, que se realizó en el municipio de Tuchín ${ }^{4}$, entre el 4 y el 7 de enero de 2013, dos actividades se destacaron por su singularidad:

- "2:00 p.m. Caravana y Recocha cultural por las principales calles"

- "3:00 pm. Ritual zenú bautizo de casa”.

Acto seguido en la programación del primer día, a las 4:00 p.m. tuvo lugar la instalación oficial del Festival. De esta manera, recocha cultural y bautizo de casa, dos prácticas ancestrales zenúes, precedieron ritualmente la inauguración de una fiesta que se extendió durante los subsiguientes cuatro días.

Aunque en el habla colombiana y especialmente en la jerga costeña la palabra recocha tiene un significado que denota desorden, tumulto y algarabía, llama aquí la atención su presentación como acto cultural. Por otra

3 Información sobre el Festival en: http://www.fundarte.comuv. com

4 La cultura indigena zenú estaba dividida desde tiempos prehispánicos en: Finzenú, que comprendía el valle del río Sinú y las áreas de Tolú, San Benito Abad y Ayapel, y era la sede religiosa del imperio; Panzenú, entre el valle del río San Jorge y la parte baja del río Cauca, que producía los alimentos y las materias primas; y Zenúfana, la sede central de gobierno, que llegaba hasta el centro del actual departamento de Antioquia, de donde procedían la mayoría de riquezas auríferas. Tuchín fue fundado el 26 de diciembre de 1826 por el indígena Manuel Talaigua Montalvo. Su nombre hace honor al cacique Tuchizunga, personaje ancestral y defensor del pueblo zenú. En la actualidad, Tuchín se erige como municipio mediante Ordenanza N. ${ }^{\circ} 09$ de 2007, siendo el más reciente de los actuales 30 municipios del departamento de Córdoba, costa Atlántica colombiana. Cuenta con una extensión territorial de $128 \mathrm{~km}^{2}$. La cabecera municipal tiene una altura de $106 \mathrm{~m}$ s.n.m, con una temperatura promedio de $28^{\circ} \mathrm{C} ; 104 \mathrm{~km}$ le separan de Montería, capital del departamento. Población total aproximada: 34.484 habitantes. Limita al norte con los municipios San Antonio de Palmito y Sincelejo (departamento de Sucre), al oriente y sur con el municipio de San Andrés de Sotavento y al occidente los municipios de Chimá y Momil. parte, ligada a esa actividad tiene lugar el bautizo de casa, una ceremonia ancestral zenú que ocurre en las comunidades cuando una familia inaugura la casa para vivir. Dicha ceremonia es precedida regularmente por una carga de casa, tradición que consiste en convocar a la comunidad para transportar una casa hecha en madera y palma desde el sitio de elaboración, hasta el lugar donde va a ser instalada definitivamente.

La recocha y el bautizo de casa son dos acontecimientos que se comprenden en su propia connotación, más allá de un protocolo festivo, en tanto varios de sus elementos como la música, el baile, el ritual y el jolgorio acompañan las faenas habituales del pueblo indígena zenú. En ese contexto, otras eventualidades no cotidianas deben adaptarse a estas matrices tradicionales, sobre todo si se trata de iniciativas culturales o educativas. Este fue el caso de los proyectos en etnoeducación emprendidos por docentes y autoridades del Cabildo Mayor del Resguardo Indígena Zenú ${ }^{5}$ durante la década de 1990.

Para efectos de esta investigación, tres antecedentes confirman las adecuaciones que unos y otros proyectos han debido conjugar con las cotidianidades festivas que destacan como matriz cultural del territorio zenú. El primero de ellos consistió en una recopilación de juegos

5 En 1773, el rey de España reconoció el territorio de San Andrés de Sotavento (departamentos de Córdoba y Sucre) como resguardo indígena. De 83.000 hectáreas, este subsistió hasta comienzos del siglo XX cuando fue disuelto mediante la Ley 55 de 1905. Desde 1969, líderes y lideresas zenúes iniciaron las luchas contemporáneas por recuperar sus tierras, decenas de estas personas fueron asesinadas. En 1990 el Estado reconstituyó el Resguardo de San Andrés de Sotavento con 10.000 hectáreas y progresivamente lo amplió hasta alcanzar 23.000 hectáreas para una población estimada en 33.000 habitantes. Las comunidades se encuentran organizadas en cabildos menores, cuyas autoridades responden administrativamente ante el Cabildo Mayor del Resguardo de San Andrés de Sotavento, encabezado por un cacique mayor. En noviembre de 2013, tuvo lugar el Congreso Extraordinario del Pueblo Zenú, que reunió a 260 delegaciones con sus respectivos capitanes menores. 
tradicionales a manera de inventario recreativo ancestral. El segundo buscaba promover la etnoeducación a través de estos juegos y manifestaciones lúdicas ancestrales en las escuelas. El tercero fue un emprendimiento de investigación sobre las condiciones de pobreza de los pueblos indígenas, el cual arrojó importantes referentes acerca de los cambios y continuidades del pueblo zenú.

\section{RETORNANDO AL MONTUCUY}

La recopilación de juegos tradicionales de los pueblos indígenas en Colombia fue un emprendimiento que inició en 1995, a cargo de dos estudiantes indígenas de la Licenciatura en Educación Física de la Universidad Pedagógica Nacional (Panqueba y Montaño, 1997) ${ }^{6}$. Esta iniciativa nace con independencia de los contenidos formativos en la universidad, pero muy ligada a la colaboración con los maestros de seis escuelas del Resguardo. El compromiso adquirido con las autoridades indígenas fue darle continuidad al proyecto después de ser presentado en Bogotá ante el jurado de la universidad. La experiencia piloto debía constituirse como fundamento para la elaboración de unas cartillas con juegos tradicionales, en búsqueda del beneficio de todas las escuelas del territorio zenú.

Si bien el foco de interés era una recopilación de juegos y juguetes (Panqueba, 2001-2006), aparecían de manera recurrente los instrumentos musicales y la realización de bailes que se conocen en la región como fandangos. Las actividades en las escuelas alternaban con fiestas de las comunidades, ceremonias como bautizos, matrimonios y funerales. Estos factores influyeron en la aceptación de los investigadores en los corregimientos, hecho que se definía en tanto participaban de estas dinámicas cotidianas.

Durante 1998, los profesionales logran un acuerdo con la Fundación Universitaria Los Libertadores, que en ese momento desarrollaba una línea de investigación en lúdica y recreación. Participando como docentes de la institución, introdujeron la iniciativa de rescatar los juegos de las regiones beneficiarias de los programas universitarios. Así, durante 1999, desarrollan la investigación "Una experiencia de etnoeducación a partir de los juegos tradicionales y manifestaciones lúdicas

6 Mención de honor en el Premio Nacional de Educación Francisca Radke, Colombia, 1998. ancestrales del pueblo indígena zenú"7 . La estrategia de las autoridades indígenas para lograr la participación comunitaria en este trabajo, consistía en hacer coincidir los eventos de la investigación con las actividades locales cotidianas. De esta manera, entre juegos, juguetes, bailes y ceremonias, las charlas sostenidas con las mujeres y hombres mayores se acompasaban con armonías de pito atravesao ${ }^{8} \mathrm{y}$ sus instrumentos acompañantes: el tambor, las maracas, el guache y la caja. La música y el baile se con-jugaron como elementos de metodología, a sugerencia explícita de las autoridades.

Con el papel central que cumplía la música de pito atravesao y el baile, para la investigación, las autoridades de los cabildos menores priorizaron como socialización de sus resultados la realización de un evento cultural donde las comunidades compartieran sus juegos, bailes, músicas, artesanías, comidas y bebidas ${ }^{9}$. Además, propusieron la producción de un material escrito basado en la historia de vida de un personaje heredero de las historias zenúes narradas en forma de décimas ${ }^{10}$. Dicho trabajo se tituló "Mi vida es una décima: registro oral del Resguardo Indígena Zenú, inspirado en el indio Banquet de Tuchín". Este giro hacia la tradición oral como portadora de saberes lúdicos zenúes fue contribuyendo a identificar los elementos de la cosmovisión que actualmente se fortalecen mediante el trabajo de grupos culturales y los emprendimientos educativos en la región.

7 Proyecto de investigación beneficiario del Programa de Estímulos a la Creación y a la Investigación del Ministerio de Cultura, convocatoria 1998: "Becas de apoyo a procesos de investigación en pedagogía artística y/o cultural. Área de Etnoeducación".

8 Instrumento musical aerófono de lengüeta simple según la clasificación de Abadía (1983). También conocido como carrizo, flauta o caña de millo, es una flauta traversa de unos 30 a $40 \mathrm{~cm}$ de longitud con cuatro orificios separados entre sí por espacios de $3 \mathrm{~cm}$. Los nombres que se le asignan dependen del material en que está elaborada (maíz millo o sorgo del interior o mijo). En la cabeza de la flauta lleva una lengüeta y una fibra de hilo que coadyuvan a producir el sonido característico (pp. 248-250).

9 "Primer encuentro por la cultura y la educación propia del pueblo indígena zenú", realizado en la comunidad de El Porvenir, el 18 de diciembre de 1999.

10 La décima es una forma de narración por estrofas que, a manera de cantos, son interpretadas por especialistas, generalmente dedicados a labores rurales. Una modalidad característica en la costa Atlántica colombiana es la pervivencia de enfrentamientos a duelo de décimas improvisadas en el momento. Algunas veces hay acompañamiento musical de guitarra. Mayor información: http://www.tradicionoralzenu.4t. com/index_2.html 
Durante 2005, las autoridades del cabildo menor de La Esmeralda Norte participaron en un estudio regional para América Latina, el cual buscaba caracterizar las concepciones que sobre la pobreza son comunes entre algunos pueblos indígenas (Panqueba, 2012) ${ }^{11}$. La realización de este trabajo contribuyó a la comprensión de las nuevas demandas que caracterizaron las luchas indígenas desde finales del siglo xx y que continúan durante la primera década del xxi (Velandia, 2003). Durante las conversaciones con el cacique Euclides Terán y otros líderes, fue esencial para los investigadores poner en práctica un ejercicio de inmersión en la fiesta y el ritual zenú. Las entrevistas transcurrieron entre una ceremonia de bautizo y cargamento e' casa, una fiesta de fandango y los bautizos a dos niñas de la comunidad. Las conversaciones con los líderes se alternaban con los bailes y los juegos de las niñas y los niños, al compás de Los Hermanos Terán, conjunto musical de pito atravesao originario de esta comunidad.

Aunque en apariencia esta investigación trataba una realidad ajena con la dinámica festiva zenú, el procedimiento convenido con el cacique Euclides Terán para conversar, es asimilable con el ambiente descrito por el sociólogo colombiano Orlando Fals Borda (Barranquilla, julio 11 de 1925 - Bogotá, agosto 12 de 2008) durante su trabajo de campo del año 1984 en esta región:

Bernabela Reondo, la nueva cacica del resguardo indígena de San Andrés de Sotavento, me tomó de la mano para conducirme a través de la cumbiamba, por debajo de las ramadas de palma hacia la esquina de la casona donde las mujeres estaban sirviendo chicha bocana de maíz. Había buenas razones para celebrar. Ese 30 de marzo de 1984, la dueña "blanca" de la hacienda de Bajogrande se había llevado en un camión a su mayordomo con unas cuantas tejas de zinc de la casa de los "mozos", para entregar la propiedad a los indígenas que la habían tomado unos meses atrás. Era la quinta finca que se "recuperaba" por aquellas lomas del departamento de Córdoba en los últimos tres años. (Fals Borda, 2002c, p. 12A).

11 Investigación titulada: "Política, pobreza e identidad étnica: estudio comparado sobre la dimensión económica de las luchas indígenas en Colombia y Ecuador con posteridad a los reconocimientos constitucionales de la diversidad étnica". Apoyada con una beca del Consejo Latinoamericano de Ciencias Sociales (Clacso) y Comparative Research on Poverty (CROP), en 2004.
En ese caso, el autor menciona la cumbiamba como una fiesta que facilita el ámbito propicio para conversar; un hecho de familiarización para comprender la lucha por la recuperación de tierras sucedida en las sabanas de los departamentos de Córdoba y Sucre. Pero la cumbiamba como manifestación cultural también permite un primer acercamiento al objeto de la presente investigación. Para ello es preciso comprender que sobre las cumbiambas o bailes de cumbia aún no existe consenso acerca de su raíz africana o americana.

El origen de la cumbiamba según varios autores, puede ser la danza "mulata y negra" (Abadía, 1983, pp. 200203, 206) "de procedencia africana" (Londoño, 1998, pp. 123-125), pero también "una danza indígena asociada a ritos agrarios" (Turbay, 1995, p. 11). Ello no ha sido óbice para coincidir en que la cumbiamba es un evento festivo donde abundan las cumbias y demás ritmos comunes en las poblaciones costeñas: porro, fandango y puyas, entre otros (Londoño, 1998, p. 123). Sin embargo, asumiendo estas manifestaciones corporales en un sentido arqueológico de la danza, en cuanto elemento inherente a la matriz cultural zenú, es preciso retomar con Fals Borda (2002c) que:

Según los estudiosos, estos bailes son los precursores más probables de nuestro porro, que toma su forma musical actual con la transición de aquellos aires de pito a la banda de viento, en una expresión que así resulta triétnica [...]. Viene a ser como el baile de cumbia, cuyos orígenes pueden remontarse al juego de montucuy y gaitas de los indios zenúes [...] (p. 126A).

Aunque el montucuy fue objeto de atención para las investigaciones antecedentes a esta, no fue posible establecer su contexto sincrónico de matriz lúdica. Sin embargo planteó un problema en el terreno diacrónico por su relación directa con la génesis de los bailes zenúes. ¿Sería este elemento una raíz/matriz americana de la cumbiamba, que luego se fue conjugando con las matrices afro e hispánica, dando origen a los ritmos actuales de la costa que son bailados e interpretados tanto con instrumentos autóctonos como foráneos?

Desde una perspectiva sincrónica, inherente a los antecedentes de trabajo descritos, ha sido importante la permanencia de la matriz cultural festiva zenú — tal vez el montucuy-, en cuanto metodología de participación activa, pero también como factor común a las luchas zenúes que han marcado su conjugación de identida- 
des con los referentes africanos e hispánicos. Por otra parte, desde una mirada diacrónica, las luchas zenúes presentan un primer momento durante la década de 1980 con la demanda por la recuperación de tierras. En un segundo momento, a finales de la década de 1990 e inicios del siglo XXI, las demandas se trasladan principalmente al ámbito de la salud, la educación y la cultura. En este contexto, las líneas temáticas generales de la presente investigación son la educación y la cultura. Retoma los tres trabajos reseñados como antecedentes metodológicos y documentales, pero también otras fuentes primarias derivadas de las actividades docentes, comunitarias y organizativas de la región. Parte de esta información fue recopilada desde hace aproximadamente diecisiete años, en formato fotográfico análogo, audiocasetes y videocasetes en formato vHS. Otras informaciones fueron recopiladas de viva voz de las personas participantes de la presente investigación.

\section{HISTORIOGRAFÍA DEL MONTUCUY}

Esta investigación aborda la dimensión corporal de la matriz cultural zenú, en cuanto fuente de las iniciativas educativas, artísticas y culturales que actualmente se desarrollan con el liderazgo de docentes y artífices de la cultura del municipio de Tuchín. Este objeto se define a partir del elemento jaracoso ${ }^{12}$ que destaca en la matríz cultural del pueblo indígena zenú, el cual es comprensible en la contemplación y descripción de los juegos, las fiestas, los bailes y las ritualidades acaecidas entre las sonoridades del pito atravesao y las gaitas, instrumentos musicales que se armonizan con tambores, guaches y tamboras.

El elemento jaracoso de las cotidianidades en territorio zenú ha sido objeto de investigación historiográfica desde por lo menos tres perspectivas. La primera remite a documentos que buscaban dar cuenta de sucesos históricos en la costa Atlántica, sobre todo las crónicas coloniales y otros informes postcoloniales (por ejemplo: el Archivo General de Indias de Sevilla, AGI; De la Torre y Miranda, 1794). La segunda perspectiva se ocupa de inventariar manifestaciones folclóricas como la música, las danzas y otras expresiones culturales. Este es el

12 Palabra empleada en la región zenú para referirse al carácter jocoso, juguetón y fiestero en acciones cotidianas. Esta palabra es constantemente pronunciada en conversaciones formales e informales para referirse a esa matriz cultural endémica de la región. caso de las investigaciones de Abadía (1984) y Zapata $(1977)^{13}$, quienes destacan la matriz cultural africana en el folclor de la costa Atlántica.

La tercera perspectiva historiográfica retoma las dos anteriores con el fin de generar reflexiones sociológicas, antropológicas e históricas respecto a la configuración cultural costeña en sus matrices africana, indígena e hispánica (Fals Borda, 1984, 1986 y 2002). En similar sentido podemos mencionar los trabajos literarios de Sánchez (1998), cuyas novelas recrean la fusión cultural africana, indígena e hispánica, presentando sin embargo una fuerte preeminencia del elemento afro. Por otra parte, en la recopilación de danzas nacionales de Londoño (1998), los inventarios folclóricos de la costa Atlántica son recreados con alusiones al carácter festivo de esta región.

\section{"Los indios se la pasaban en juegos} de montucuy y gaitas"14

Si bien las referencias al carácter jaracoso del ethos costeño (Fals Borda, 2002c, p. 87A) no constituyen un objetivo central en las perspectivas historiográficas mencionadas, su reconstrucción a modo de arqueología del saber permite identificar la recurrencia del montucuy como elemento inherente de la costeñidad. Con esta palabra vernácula de las sabanas de Córdoba y Sucre, los textos revisados aluden de manera explícita o implícita a la jaracosidad indígena zenú. En primera instancia, Fals Borda (2002a, p. 155B) refiere al montucuy como un evento de juego donde hay bebidas alcohólicas y borracheras, a partir de fuentes de archivos históricos con referencias como:

[...] El visitador Jacinto de Vargas Campuzano prohibió a su vez a los indios zenúes el juego de "montucuy" en la región de sabanas de la Costa, en 1675, por ser "juntas y borracheras de jugo o vino de las palmas, aguardiente, chicha y otras cosas con que se embriagan [...] y las gaitas [como baile] de que se dice haber demasiado abuso". (AGí, Escribanía de Cámara 644, Cuaderno 2, fols. 278v-279). Pero esta decisión tampoco tuvo aceptación popular. Al

13 Estudio descriptivo de las manifestaciones tradicionales de la cultura popular colombiana, sus raíces y localización. El texto es una exposición exhaustiva de las regiones colombianas con una caracterización de los instrumentos musicales sus materiales y estructura; las coreografías de las danzas y sus particularidades regionales. El apoyo de fotografías y dibujos complementan la investigación.

14 Fals Borda (1986) p. 16A 
contrario, se sabe que en las fiestas de indios participaban españoles que llegaban hasta pintarse y vestirse como los indígenas y jugar "piquerías" con ellos. (AGÍ, Santa Fe 492, Cuaderno l. fols. 20-22, 26).

Aunque no existe una descripción que aclare en qué consistía el juego del montucuy, es importante en la anterior cita la mención de algunos elementos materiales e inmateriales que conforman su ámbito y lo hacen visible. Dicha visibilidad se prestó, sin embargo, para elucubraciones de poder; por ejemplo un hecho acaecido durante la década de 1660, cuando el ambiente jaracoso zenú fungió como argumento para que la encomendera Ana Vitalina Fuentes no pagara debidamente a las mujeres y hombres zenúes por las extenuantes tareas impuestas a diario. En uno de los libros de cuenta y razón de sus haciendas aparece la relación de pagos en especie, donde se visilibiza con desdeño el comportamiento festivo de la gente zenú: “[...] En general prefería pagar en ropa y no en efectivo, porque los indios se la pasaban en juegos de 'montucuy' y gaitas (juntas de vino de palma, aguardiente y chicha) [...]" (Fals Borda, 2002c, p. 16A). En este caso, la encomendera se reservaba la censura de estos juegos, probablemente porque en el montucuy había derroche de dinero. Sin embargo, es un señalamiento que posteriormente se iría convirtiendo en alusión peyorativa de la jaracosidad zenú.

Pese a las interpretaciones múltiples que tienden a despreciar este comportamiento jaracoso, es importante resaltar que gracias a su permanencia, se surtieron acciones de adaptación que la población indígena ha empleado para sobrellevar las condiciones impuestas por las sucesivas colonizaciones en las sabanas de Córdoba y Sucre. Este destino ha sido sorteado desde una actitud lúdica desde la risa y la burla como transformación efímera - tal vez- de las condiciones materiales desventajosas:

La visita del oidor Villabona ayudó a los indígenas costeños, pero no desarraigó los abusos que contra ellos se venían cometiendo. Un protector de naturales llamado Lorenzo de Aponte, después de un siglo, todavía se quejaba en San Andrés-Mexión hasta de los curas, pues estos cometían los mismos crímenes de que hablaba el doctrinero de 1581. Pero también observaba que a muchos indios no parecía importarles la situación, pues respondían pasando gran parte del tiempo contando cuentos, burlándose y jugando montucuy, además de que festejaban mucho con vino de palma. Algunas comunidades indígenas de la depresión momposina no solo sobreaguaban el cambio sino que se transformaban en pueblos mestizos y zambos, con toda la algarabía y el fósforo del caso (Fals Borda, 1984, p. $50 \mathrm{~A})$.

Esta interpretación del montucuy que lo relaciona con burlas y cuentos, en cuanto juegos de palabras, coincide con el componente lúdico lingüísitco de la necesaria lucha agonal por el honor. En tal situación, según Huizinga (1987) cada participante en un escenario de juego lanza porfías a sus contrarios, siempre buscando el sostenimiento del combate en un plano lingüístico; y el juego transcurre en porfías nobles (p. 123). En tal sentido, el montucuy presenta otro elemento con el que actualmente es reconocida la población costeña: su habilidad para transformar lingüísticamente una situación cotidiana convirtiéndola en motivo de risa.

Por otra parte, Ocampo (1993) atribuye a la fiesta un papel fundador y constitutivo de sociedad e identidad de la población sinuana, de donde rescata que al montucuy se le consideraba una "actividad prohibida o suspecta" (p. 113). Las estigmatizaciones que recayeron para las prácticas y formas de vida zenúes no escaparon del sentido común que señala a las personas costeñas como perezosas, fiesteras, parranderas y poco trabajadoras. Sin embargo es nuevamente Fals Borda quien ofrece un interesante giro de análisis sobre el tema, el cual si bien permanece al margen de una profundidad en cuanto a las perspectivas corporales, ofrece en cambio una perspectiva del ámbito fiestero como un elemento que permitiría un con-juego interétnico e intercultural. En este sentido, describe las contribuciones a las fiestas que la gaita recta de boquilla de cera o la caña de millo hicieron a los bailes de tambores y coros, con la participación de las esposas de los hacendados que vendían dulces y aguardientes:

Súmense estos elementos y añádanse las carreras de caballos con jinetes acoplados, la esgrima a machete, la pólvora y el ron ("ñeque" o "chirrinche") y resultará la gran fiesta costeña típica de hoy, la que en el siglo XIX se plasmó en corralejas para manteros y garrocheros, y en fandangos de plaza con cumbias formadas en círculo y bandas de viento o acordeón de botones. Estas son experiencias sociales directas de nivelación de clases y conductas que forman parte intrínseca de la cultura costeña triétnica y anfibia: por ejemplo, la cumbia como baile viene a ser precisamente una síntesis del aporte musical de las tres razas. (Fals Borda, 2002a, pp. 154B-156B). 
A esta amalgama se le ha tildado históricamente como libertinaje, un estilo de mestizaje que fungió en las sabanas del río Sinú como química de genes, costumbres e ideas en un ámbito de tolerancia que ha formado la personalidad costeña que describe Fals Borda (2002a) como:

Alquimia fecunda y cálida en ebullición permanente que signa el ethos de nuestra región e irradia su euforia al resto de la comunidad colombiana. Típico de ese buen genio y de esa alquimia de alegría y tolerante actividad ha sido la transformación del impulso bélico o violento - tan destructivo en las irritables provincias del interior andino- en las piquerías o "guerras" comunales de empuje y aguante (según barrio, caserío o pueblo) expresadas en jolgorio, comida, fiesta e intercambios solidarios, todo con buen humor y "mamando gallo" (p. 59B).

Este carácter de la costeñidad que si bien recoge elementos festivos, ha sido interpretado por Fals Borda (1984) como un complejo del dejao (p. 172A) que pasa por irreverente, en tanto ha dado lugar a las luchas indígenas de la costa Atlántica durante el siglo xx. Pero también ha permitido unas relaciones interétnicas generadoras de nuevas identidades que han acuñado mecanismos de supervivencia social que se expresan en acomodaciones (p. 44B), "simbiosis y sincretismos" (p. 65B). Su caracterización cronológica fue uno de los aportes de Fals Borda, quien distinguió cuatro fases: 1) un ethos filantrópico inicial, 2) curiosidad y adopción selectivas, 3) contraviolencia y 4) dureza cultural (p. 39B).

La primera corresponde al carácter no-violento de la población zenú, resaltando la receptividad pacífica que encontraron los españoles. En la segunda resalta la capacidad de asombro ante la novedad y la adaptación al idioma español y a las herramientas foráneas para sus labores cotidianas. La tercera explica los motivos para enfrentar la violencia con el nombramiento de caciques proclives a los enfrentamientos bélicos, además de seguir el impulso de las luchas cimarronas emprendidas por los esclavos africanos. En la cuarta destaca las estrategias de sobrevivencia ante las enfermedades desconocidas, el trato violento y otras que requerían capacidad de aguantar con firmeza, pero también con sumisión sin perder el sentido del humor.

\section{TUCHÍN: PATRIMONIO QUE BUSCA SU MATRIZ}

Según Fals Borda (1984) "La resistencia adquirida y desarrollada en las décadas de la posconquista sirvió igualmente para hacer frente a la furiosa ofensiva latifundista y capitalista que tuvo lugar en esta región durante la segunda mitad del siglo XIX" (p. 44B). De esta manera se hacen más comprensibles los acontecimientos que durante la segunda mitad del siglo $\mathrm{xx}$ hicieron que en territorio zenú se fermentaran las luchas por la recuperación de las tierras y posteriormente, los emprendimientos actuales de dinamización cultural que contemplan desde la promoción de agrupaciones folclóricas, hasta la declaratoria del sombrero vueltiao como Símbolo Cultural de la Nación (Secretaría del Senado, 2004). De allí han emergido temas como el del reconocimiento de los sitios sagrados como patrimonio tangible, discusión que se enmarcaría en el mismo sentido de lo que Larrain (2009) enuncia como patrimonialización del sombrero vueltiao.

A partir de la confluencia de temáticas territoriales, culturales, mediáticas y artesanales en el territorio zenú, se fue abriendo una inusitada línea de producción audiovisual que ha abarcado, además de la declaratoria de patrimonio en crónicas como la del canal de Alberto Salcedo R. (2011), temas sobre el contexto de producción artesanal a partir de la fibra de caña flecha, junto a otras como la de González, González y Pardo (2012), que re-crean viajes al mundo zenú para posicionar a Tuchín como hito turístico regional. Por otra parte, en una pieza audiovisual de Señal Colombia (Oliveros, 2012), este municipio cordobés se proyecta como el referente de la cultura zenú contemporánea, dada su intensa dinámica cultural sustentada en la elaboración del sombrero fino vueltiao, como principal fuente de identidad y de dinamización económica.

En la producción audiovisual la recuperación de las tierras continúa siendo tema de primer orden, además del fortalecimiento cultural y organizativo. De allí que también las piezas comunicativas aborden la conciencia étnica de las juventudes y de nuevas comunidades en proceso de recuperar sus formas de organización indígena, tal como es presentada la pieza de Red Visual (Asencultura, 2012), cuyo relato refiere a la creación de un cabildo en el municipio de Necoclí, (Antioquia); 
recoge los orígenes del pueblo zenú y resalta la participación de algunos líderes del resguardo de San Andrés de Sotavento y de las gestoras y los gestores de la comunidad en reconstrucción. Por su parte, la pieza de comunicación comunitaria de Nuevos Decimeros (2012) relata los emprendimientos de las juventudes zenúes hoy asentadas en el departamento de Antioquia, con el objeto de relacionarse de manera directa con su territorio madre en el Resguardo de San Andrés de Sotavento. En los guiones también son comunicados los emprendimientos de gestión, formación e investigación cultural a cargo de docentes, gestores y gestoras zenúes.

En este inusitado auge audiovisual acerca del territorio zenú, es importante resaltar la musicalización empleada en las piezas documentales. Todas ellas se ambientan con música de gaitas y pito atravesao, o en algunos casos con vallenatos. En algunas escenas hay alusiones a los bailes escenificados en este territorio, además de enfatizar el tema de la presencia de ritmos africanos en las músicas, como en la crónica audiovisual de Señal Colombia (2012, a partir de 6 min 24 s). Y aunque también existen producciones que específicamente se ocupan de la música y la danza, sus contenidos aún reflejan una tendencia folclórica que se asemejaría con los señalamientos peyorativos frente al montucuy o al carácter jaracoso de la costeñidad.

No obstante la existencia de compilaciones, audiovisuales y otros documentos: "La historia de la música costeña (a pesar de esfuerzos meritorios como los de los hermanos Zapata Olivella, Abadía Morales, Ocampo López, Valencia Salgado, Araújo Noguera y otros) está por escribirse" (Fals Borda, 2002b, p. 116B). Lo propio sucede con las danzas, especialmente en territorios donde la identidad étnica es objeto de reconstrucción y la convivencia es intercultural. En este sentido, las herencias corporales zenúes correspondientes con la matríz cultural jaracosa, permiten recorrer los saberes milenarios de las culturas que allí se encuentran. Los antecedentes de la presente investigación permitieron identificar algunas confluencias de patrimonios corporales ancestrales (Panqueba, 2014) en las relaciones entre comunidad educativa y escuela como territorio para las interculturalidades, sobre todo a partir de la práctica de danzas, músicas y juegos. Aquellos ejercicios de recopilación plantearon la interrogante por la matriz cultural de estas prácticas, siendo imposible su abordaje por la especificidad del juego como objetivo planteado al principio. La presente propuesta aborda dicha matriz.

\section{EL CARGAMENTO E' CASA: JORNADA, SÍMBOLO, TERRITORIO Y RITO DEL MONTUCUY}

El 24 de julio de 2014, el pueblo de Tuchín celebró el séptimo aniversario de haberse erigido como municipio. Los barrios organizaron comparsas alusivas a las costumbres y vida cotidiana tuchinera. Una de las comparsas hizo homenaje a los cargamentos de casa. En ella, las personas adultas del barrio Libertad construyeron una pequeña casita con techo de palma con el fin de llevarla por las principales calles de la cabecera municipal. Su baile fue animado al ritmo musical de la guaracha, una vertiente del género vallenato que tuvo auge entre la población zenú durante la década de 1980. Esta representación simbólica fue complementada con unas horquetas, unos calabazos para llevar la chicha y una cabuya amarrada en la parte frontal de la casa. Esta era guiada por la capitana del barrio, completando así el homenaje para esta actividad cotidiana del territorio zenú.

Esta comparsa representa un hecho cotidiano inédito para otras regiones del país. El territorio zenú ha sido trenzado por sus hombres y mujeres desde tiempos ancestrales. Las manos que trenzan las fibras de caña flecha para el sombrero vueltiao también cargan casas, colocando una impronta de vida inédita para otros territorios.

Los cargamentos de casa son celebraciones rituales, eventos festivos y actos de la cotidianidad indígena zenú. Mover la casa fortalece los compadrazgos y las solidaridades en torno al esfuerzo físico, animando las energías con alimentos, bebidas y distintas manifestaciones de jolgorio. Durante un cargamento e' casa se revive el montucuy ancestral zenú. Es decir, una jornada de conjugación similar a las que describen los documentos coloniales como: juntas de vino de palma, aguardiente y chicha donde habían juegos y bailes con música de gaitas.

Cada cargamento e' casa conjuga los patrimonios corporales ancestrales, destacando los momentos característicos de cualquier otro espacio de conjugación ritual: convocatoria comunitaria anticipada; preparación de comida para todas las personas asistentes; disponibilidad de bebidas tradicionales como el ron ñeque, la chicha bocana de maíz y el masato. Las cargas de casa son epicentro para compartir los sabores de la gastronomía zenú. Comidas y bebidas tradicionales alimentan estas 
jornadas. Mover la casa dinamiza los compadrazgos, las amistades, las vecindades, las solidaridades entre los miembros de las comunidades zenúes.

Derivado de ese espíritu comunitario de labor afloran frases jocosas de juego entre quienes participan. Se evocan otros cargamentos, destacando momentos que arrancan risas. Durante el esfuerzo físico van surgiendo gritos y otras manifestaciones de animación cantadas o recitadas. Por ello, en estas jornadas ocupan principal lugar los saberes orales. Guapirreos, bromas, cuentos, anécdotas, pies de décimas e improvisaciones evocan voces jocosas en juegos de palabras.

La animación musical en un cargamento e' casa corre por cuenta de agrupaciones de pito atravesao y gaita corta, así como por las popularmente conocidas bandas papayeras, cuyo repertorio deriva de las grandes bandas que interpretan aires musicales del Caribe colombiano como porros y fandangos, entre otros. El ambiente musical también se suele complementar con el empleo de aparatos amplificadores de sonido, como los llamados picó (pick-up), donde van desfilando géneros como la guaracha, los porros, las cumbias y la champeta. En los descansos del cargamento pueden escenificarse cortos movimientos de baile que al final confluyen hacia improvisadas fiestas.

\section{EL DOCUMENTAL DEL CARGAMENTO E' CASA}

El trabajo de escritura resultante de la investigación, priorizó la interpretación in situ en las voces de los personajes, sus adaptaciones históricas y cotidianas, así como su interacción con los medios de difusión audiovisuales, escritos y gráficos, además de aquellos derivados de la vida en internet. De esta manera, fuimos informando e intercambiando comentarios sobre las actividades, a través de un grupo virtual en la red social Facebook (accesible en el enlace: https://www. facebook.com/groups/montucuy/). Tal ilación hizo posible la producción y realización documental de Muis Kanoba (Panqueba y Huérfano, 2014) que lleva por título Cargamento é casa, conformado por cinco segmentos: el primero dedicado a los cargamentos de casa; el segundo a las festividades zenúes; el tercero a los juegos ancestrales; el cuarto a los saberes orales; y el quinto a la gastronomía del territorio zenú.
El cargamento e' casa como un poder sígnico e icónico, emprende y lidera una historia que concreta y determina en imagen y objeto simbólico. La pieza audiovisual Cargamento $e^{\prime}$ casa es la metáfora fotográfica que hace memoria y también aquella que recrea e ilustra el pasado y el presente de la cultura Zenú. Ese conjunto secuencia- de imágenes en movimiento, de las gentes cargando y compartiendo los saberes orales, es única, plausible y digna de reproducirse, de dejarse correr y contemplar. Ella marca el camino, el arriba y el abajo: es un arca de la memoria.

En el documental, la casa camina con una sola cabeza visible: su techo. Entretanto, sus cimientos son los pasos de los hombres que ofician como vigas que van moviendo la memoria del oikos griego, de la vivienda en traslado. Dada la densidad de las fases del cargamento, gruesas en su significado, van acompasadas con la música de pito atravesao y de gaita corta, evocando los cargamentos que se suceden cualquier fin de semana en territorio zenú. La música contribuye en la organicidad contemplativa de la pieza. Los textos van orientando a quienes tienen menos familiaridad con las costumbres y formas zenúes. Ese hogar cargado tiene voz y vida por quienes la guarecen: sus cargadores. El ritmo son ellos: sus voces, no tan entendidas, fusionadas con el esfuerzo y el canto, la energía de sus ancestros.

El documental es la carga de casa y con él todo lo que la contiene y deriva: quienes ayudan, la habitan, quién cede el terrero, quién vive allí, qué hace, por qué le cargaron la casa. El cargamento es el centro y el espiral. Por ahí pasan las gentes y sus cotidianidades, sus bebidas, sus artesanías, sus modos de nominar el territorio, los sentidos comunicativos - la décima, el chiste...-, todo, fluye y confluye allí. Porque la casa es el territorio que mueve las vidas de quienes la cargan, sus historias, sus pasados y presentes: su recreación y resemantización. El cargamento e' casa es un sí mismo un territorio montucuy.

Durante la filmación del documental Cargamento e' casa, tuvimos la participación del programa "Semillas de vida del pueblo zenú", que es la adaptación al medio indígena de la "Estrategia Nacional de Atención Integral a la Primera Infancia, que busca aunar los esfuerzos de los sectores público y privado en favor de la primera infancia de Colombia". La actividad tiene lugar en el marco del "módulo festejar", el cual es implementado en todos los Centros de Atención Infantil del Resguardo Indígena Zenú. Dada la temática de la investigación sobre el mon- 
tucuy, fue importante encontrar que los cargamentos de casa fuesen dinamizados en el programa "semillas de vida" en el marco del tema de las festividades zenúes. En esa perspectiva, las maestras, las madres de familia, los maestros y papás de niñas y niños se integraron en una actividad que resultó evocadora de los preparativos necesarios para un cargamento $e^{\prime}$ casa cotidiano.

\section{CONCLUSIONES}

Las re-creaciones contemporáneas de las prácticas corporales ancestrales representan su introducción en distintos contextos a través de nuevas estrategias antiguas. Si bien ello puede leerse desde Occidente como una moda, expresada en una suerte de esencialismo étnico, una lectura con-jugada como la propuesta en la presente investigación exige un análisis multidimensional. Unos y otros manejos pueden ser asumidos desde la perspectiva de los patrimonios ancestrales que pueden ser aprovechados pedagógicamente, a la manera de estrategias rebasando el simbolismo del folclor nacionalista. La práctica de las danzas, músicas y rituales zenúes o su re-creación en distintos formatos, es una herencia y un

\section{REFERENCIAS BIBLIOGRÁFICAS}

Abadía, G. (1984). Compendio General de Folklore Colombiano. Bogotá: Biblioteca Banco Popular.

Agamben, G. (2007). Infancia e historia. Buenos Aires: Adriana Hidalgo Editora.

Asencultura [Red Visual]. (2012, abril 21). Territorio para los Zenú. [Archivo de video]. Recuperado de: https:// www.youtube.com/watch?v=UNhUMwDz2TI

De la Torre y Miranda, A. (1794). Noticia individual de las poblaciones fundadas en la provincia de Cartagena. Santa María: Impreso por don Luis Luque y Leyva.

Fals Borda, 0. (1984). Historia doble de la costa. Tomo III. Resistencia en el San Jorge. Bogotá: Universidad Nacional de Colombia, Banco de la República, El Áncora Editores.

Fals Borda, 0. (2002a [1979]). Historia Doble de la Costa. Tomo I. Mompox y Loba. Bogotá: Universidad Nacional de Colombia, Banco de la República, El Áncora Editores.

Fals Borda, O. (2002b [1981]). Historia doble de la Costa. Tomo II. El presidente Nieto. Bogotá: Universidad Nacional de Colombia, Banco de la República, El Áncora Editores. fruto de aquella matriz jaracosa que acoge pero, a su vez, ofrenda los saberes del montucuy. Es decir, las ciencias y los conocimientos expresados en la cotidianidad costeña como recocha, desorden, fiesta, fandango y cumbiamba. De esta manera:

Una experiencia originaria, lejos de ser algo subjetivo, no podría ser entonces sino aquello que en el hombre está antes del sujeto, es decir, antes del lenguaje: una experiencia muda en el sentido literal del término, una in-fancia del hombre, cuyo límite justamente el lenguaje debería señalar (Agamben, 2007, p. 64).

En los emprendimientos de interculturalidades actuales, ya sea por las interacciones entre pedagogías o por el entrecruce de manifestaciones diversas, las descripciones de experiencia son a la vez teorías que se practican desde la infancia en interdependencia de lenguajes corporales y simbólicos. Este es el círculo retornante entre experiencia e infancia, siendo esta última la cuna propia de la primera; coexisten cronológicamente y entonces producen personas con capacidad de decirse y hacerse en sus propias historias.

Fals Borda, O. (2002c [1986]). Historia doble de la costa. Tomo IV. Retorno a la tierra. Bogotá: El Áncora Editores (Carlos Valencia Editores, 1986).

González, J.; González, G. y Pardo, L. [Jesús González]. (2012, octubre 12). Bitácora cultura zenu. Parte 1. [Archivo de video]. Recuperado de: http://youtu. be/U_wcPAnKeA8?t=13m27s

Huizinga, J. (1987). Homo Ludens. Madrid: Alianza Editorial.

Larrain, A. (2009). A patrimonialização da arte e da cultura indígena na Colômbia 0 caso do sombrero vueltiao. Tellus 9(17), 207-229. Recuperado de: http://www.tellus.ucdb.br/index.php/tellus/article/ download/193/224

Londoño, A. (1998). Danzas colombianas. Bogotá: Universidad de Antioquia.

Nuevos Decimeros. [Nuevos Decimeros]. (2012, mayo 24). El viaje de Zenufana a Finzenú. [Archivo de video]. Recuperado de: http://vimeo.com/42804782 
Ocampo, G. (1993), Entre la localidad y la nación. Aspectos políticos de la construcción de identidades en un contexto regional. Revista Colombiana de Antropología, 30, 103-127.

Oliveros, N. [Señal Colombia]. (2012, diciembre 24). Los puros criollos. Capítulo 7. El sombrero vueltiao. [Archivo de video]. Recuperado de: https://www. youtube.com/watch?v=Zn4z6jE30oo

Panqueba, J. (2001-2006). Juegos y juguetes ancestrales. Video clips. Bogotá. Recuperado de: https:// drive.google.com/folderview?id=0B69Lf_c31P9g SXNZQTZSRy14RFE\&usp=sharing\&tid=0B69Lf_ c31P9gc0tNOUZOWExnSFk

Panqueba, J. (2012). Elaboración y negociación de la pobreza indígena. Jugosas ganancias para el desarrollo capitalista en Ecuador y Colombia. En: Las relaciones internacionales de la pobreza en América Latina y el Caribe (pp. 291-327). Buenos Aires: Consejo Latinoamericano de Ciencias Sociales (Clacso).

Panqueba, J. (2014). Kwitara Santayá u'wbohiná-kueshro. Conjugación de patrimonios corporales ancestrales en Bogotá: territorio muisca de Bosa. Kinesis, Revista del Centro de Educação Física e Desportos da Universidade Federal de Santa Maria 31(2), 75-96.

Panqueba, J. (2001- 2006). Juegos y juguetes ancestrales video clips. Bogotá: Google Drive. Recuperado de: https://drive.google.com/folderview?id=0B69Lf_c3 1P9gSXNZQTZSRy14RFE\&usp=sharing\&tid=0 B69 Lf_c31P9gc0tNOUZ0WExnSFk

Panqueba, J. y Huérfano, A. [MuisKanoba]. (2014, noviembre 27). Cargamento e' casa. [Archivo de video]. Recuperado de http://youtu.be/m-y-00nd8-M

Panqueba, J. y Montaño, V. (1997). Una chicha por los juegos ancestrales de los sinúes. Tesis de Licenciatura en Educación Física. Bogotá Universidad Pedagógica Nacional.

Salcedo, A. [Canal de AlbertoSalcedoR]. (2011, enero 13). Los sombreros de Tuchín. [Archivo de video]. Recuperado de: https://www.youtube.com/ watch?v=Wu0D1VcnxHg

Sánchez, D. (1998). Danza de redención. Bogotá: Editorial Grijalbo.

Secretaría del Senado (2004). Ley 908 del 8 de septiembre de 2004. Por la cual se declara Símbolo Cultural de la Nación el Sombrero Vueltiao, y se hace un reconocimiento a la cultura del pueblo Zenú asentada en los departamentos de Córdoba y Sucre. Diario Oficial, 45.666, 9 de septiembre.

Turbay, S. (1995). De la cumbia a la corraleja: el culto a los santos en el bajo sinú. Revista Colombiana de Antropología, 32, 6-40 Recuperado de: http:// kt.micrositios.net/action.php?kt_path_info=ktcore. actions. document.view\&fDocumentId=16964\&force open

Velandia, D. (2003). Liderazgo Indígena. Institución Política y Tradición de Lucha en el Pueblo Zenú. Monografía Antropología Social. Bogotá: Departamento de Ciencias Humanas, Universidad Nacional de Colombia.

Zapata, M. (1977). Folclor en los puertos colombianos. Bogotá: Fundación Colombiana de [Canal de AlbertoSalcedoR]. (2011, Enero 13). Los sombreros de Tuchín Investigaciones Folclóricas. [Archivo de video]. Recuperado de: https://www.youtube.com/ watch?v=Wu0D1VcnxHg 